Seth, K., and Kraft, A. (Host). (2017, April 15). We're back! Let's catchup and talk to Dr. Klawe from Harvey Mudd. Diversity Sauce [Audio podcast]. Retrieved from https://www.joinkidmap.org/ diversitysauce/2017/4/28/interview-with-dr-maria-klawe-president-of-harvey-mudd-college

Xia, R. (2017, January 24). Most computer science majors in the U.S. are men. Not so at Harvey Mudd. LA Times. Retrieved from http://beta.latimes.com/local/lanow/la-me-ln-harvey-mudd-techwomen-adv-snap-story.html

\title{
Developing Leaders to Tackle "Our" Problem
}

Cathleen Clerkin and Marian N. Ruderman

Center for Creative Leadership

Miner et al. (2018) make a compelling argument for the need to examine gender inequity in STEM from a social-structural lens. We completely agree. We also commend the authors for including practical recommendations for industrial and organizational (I-O) psychologists, as such implementation plans are vital if we are to move this issue from theory to practice. However, while the recommendations put forth by the authors are needed, we believe additional approaches are necessary to create marked change in gender parity in STEM. In particular, we propose that I-O psychologists (along with human resource $[\mathrm{HR}]$ professionals) need to actively engage organizational leaders if we want to successfully advance more women in STEM fields.

If we accept that gender disparity in STEM is largely due to socialstructural forces, we must also accept the need to shift these forces within organizations if we desire sustained improvement. To change the beliefs and practices of everyone in organizations, we must start with leaders. Leaders have the power, authority, and resources to influence interpersonal interactions and organizational norms. Research has demonstrated that leaders set the tone when it comes to everything from ethics (Huhtala, Kangas, Lämsä, \& Fedlt, 2013) to learning and innovation (García-Morales, JiménezBarrionuevo, \& Gutiérrez-Gutiérrez, 2012). Valerio and Sawyer (2016) have shown that leaders can also set the tone when it comes to gender equity. Given this, we believe that leaders play a critical role in modeling, supporting, advocating, and sustaining gender parity practices in STEM work environments.

A core challenge for I-O psychologists is to facilitate getting STEM leaders involved in understanding and acting on "our" problem of gender

Cathleen Clerkin, Center for Creative Leadership; Marian N. Ruderman, Center for Creative Leadership.

Correspondence concerning this article should be addressed to Cathleen Clerkin, Center for Creative Leadership, 1 Leadership Place, Greensboro, NC 27438. E-mail: clerkinc@ccl.org 
parity. As leadership development experts, we know that there is often an implementation gap between human resource intentions and leader enactment (Piening, Baluck, \& Ridder, 2014). In other words, HR policies and information do not always get prioritized or internalized by leaders, and without leaders' investment, many initiatives do not gain the momentum required to change organizational norms. I-O psychologists can play a critical role in bridging this gap by designing and implementing leadership development initiatives that provide leaders with the understanding, motivation, and resources necessary to create a structure supportive of gender parity. There are many leadership development techniques that can help individuals understand structural dynamics and how to modify them, including simulations of systems, action-learning teams, mentoring, and coaching. Regardless of method, the aim should be to add gender acumen as a core piece of leadership development curriculum.

We realize this is easier said than done. However, we believe that I-O psychologists can use their understanding of gender in organizations in combination with a social-structural lens to help facilitate this critical shift. To illustrate, we provide evidence as to why engaging leaders is necessary to dispel each of the myths outlined by Miner et al. (2018), along with examples of how I-O practitioners can implement initiatives to help leaders address "our" problem.

\section{Myth 1: Women are not masculine enough to succeed in male-dominated workplaces.}

The focal article provides excellent suggestions for how I-O psychologists can help redesign selection systems to minimize implicit bias. However, this strategy will not go far without the advocacy of leaders. There is evidence that selection tests rely heavily on the whims of leaders-who may override them as a favor for a friend or interpret them more harshly for a female candidate (Dobbin \& Kalev, 2016). Moreover, leaders are generally responsible not only for signing off on new employees but also for their subsequent development and promotion. As such, if leaders believe that women are too feminine to succeed in STEM, they are likely to overlook their female employees. Indeed, research shows that once hired, women tend to get fewer stretch assignments (Ohlott, Ruderman, \& McCauley, 1994) and less constructive feedback (King et al., 2012). This combination makes it harder for women to learn the skills necessary to succeed, creating a vicious cycle between lack of development and promotion.

This pattern is unlikely to change unless leaders are made aware of such issues through leadership development training. For example, leaders should be coached not only on how to give feedback but on the bias toward giving women vague, personal, and unhelpful feedback. 
Such training could make a big impact, as King et al. (2012) suggest that gendered differences in feedback may be well-intentioned "protective hesitation" on the part of leaders. In other words, leaders may be afraid of discouraging or upsetting women by giving them critical feedback, and may not realize that they are damaging women's careers by not providing them with clear performance information. Helping leaders to better understand the interactions between gender and opportunities to learn is essential for dealing with "our" problem.

Importantly, leaders must be invested in the desire to create gender equity; otherwise, training is unlikely to do much good. Research shows that attempts to decrease prejudice can backfire if individuals feel that they are being forced to conform through mandatory training or threats of negative consequences; conversely, programs that are voluntary, framed positively, and create long-term engagement (such as mentoring programs or diversity task forces) tend to get more positive results (Dobbin \& Kalev, 2016). One way to spark leaders' engagement with gender equity issues is through using action learning methods. Action learning involves having a group investigate a real problem (such as gender parity in STEM), take action, and reflect on lessons learned as a collective. This technique helps people gain investment through inquiry and could broaden leaders' capacity to see the social-structural roots of gender-related issues.

\section{Myth 2: Women choose not to have STEM careers.}

As detailed by Miner et al. (2018), many women choose careers outside of STEM fields, and I-O psychologists should help create educational settings that encourage women to start STEM careers. However, women also frequently leave established careers in STEM. Because of this, organizational leaders need to understand and adjust the dynamics that are driving women away. For example, many women choose to leave STEM to escape the gender/sexual harassment that is prevalent in STEM fields (De Welde \& Laursen, 2011). Indeed, research shows that male-dominated workplaces and traditionally male-oriented tasks are strong antecedents of sexual harassment (Fitzgerald, Drasgow, Hulin, Gelfand, \& Magley, 1997).

Given these dynamics, STEM leaders need to have a deep understanding of power, privilege, and social identity in order to effectively mediate gendered conflicts and create a culture that is gender inclusive. This is not easily done. Leaders who hold power and privilege may find it difficult to accurately perspective take, and simple knowledge transfer is unlikely to be sufficient. Moreover, as mentioned previously, training that is framed as punishment is unlikely to yield improvements. Instead, we recommend that leaders (and others) go through immersive learning programs that provide individuals with first-hand experiences on the dynamics of power. Barry Oshry's 
"The Power Lab" is an example of such a total immersion experience (Oshry, 1999). Like action learning techniques, simulations can help individuals understand gender issues as systemic conditions rather than individual choices.

Furthermore, when attempting to cultivate a climate welcoming of women, I-O psychologists should help HR groups and leaders understand that gender-neutral is not the same as gender-inclusive. In our experiences working with leaders, we have found that well-meaning individuals often think the solution to gender disparity is to adopt "gender blindness"- for example downplaying or ignoring gender. However, what is touted as genderblind is often implicitly male, and ignoring gender is rarely effective at advancing gender equity.

\section{Myth 3: Women are not ideal workers.}

We agree with the focal article that altering the notion that women are not ideal workers requires revising job designs and policies to allow for more flexibility, remote work, and work-life balance. However, it is not enough to create policies: organizational leaders need to create a culture that supports using said policies. For example, the recent trend of offering limitless vacation days holds the promise of infinite flexibility; however, in practice it often results in employees taking less time off (McIntyre, 2016). This is because such policies introduce ambiguity about work-life norms, and without leaders explicitly stating and facilitating expectations, workers avoid taking time off for fear of being seen as a "slacker." Furthermore, although work-life balance efforts benefit both men and women, research suggests that people still consider such challenges a women's issue-even when policies are available to all employees (Smithson \& Stokoe, 2005).

For these reasons, leaders need to be role models and advocates in order to shift cultural beliefs about the ideal worker. Leaders should receive worklife management coaching and be educated on how taking time away from work can aid productivity and provide leadership lessons. They also need to embody work-life balance themselves: if leaders are workaholics, the implicit expectation is that everyone else should be as well.

\section{Conclusion}

We wholeheartedly believe that the social-structural lens is necessary to cultivate gender equity in STEM fields. But working with HR departments to revise job descriptions, job designs, and polices is only part of the solution. We challenge I-O psychologists to use this lens to implement leadership development strategies as well. We need to get leaders educated, engaged, and invested in gender parity. Leaders, in turn, need to role model appropriate actions and attitudes. It is not enough to agree that organizations "should" promote gender equity-leaders need to "walk the talk" if we are to see a 


\section{shift the social-structural forces that currently derail women from obtaining their full potential in STEM fields.}

\section{References}

De Welde, K., \& Laursen, S. (2011). The glass obstacle course: Informal and formal barriers for women Ph.D. students in STEM fields. International Journal of Gender, Science and Technology, 3(3), 571-595.

Dobbin, F., \& Kalev, A. ( July, 2016). Why diversity programs fail. Harvard Business Review. Retrieved from https://hbr.org/2016/07/why-diversity-programs-fail

Fitzgerald, L. F., Drasgow, F., Hulin, C. L., Gelfand, M. J., \& Magley, V. J. (1997). Antecedents and consequences of sexual harassment in organizations: A test of an integrated model. Journal of Applied Psychology, 82(4), 578-589.

García-Morales, V. J., Jiménez-Barrionuevo, M. M., \& Gutiérrez-Gutiérrez, L. (2012). Transformational leadership influence on organizational performance through organizational learning and innovation. Journal of Business Research, 65(7), 1040-1050.

Huhtala, M., Kangas, M., Lämsä, A., \& Feldt, T. (2013). Ethical managers in ethical organisations? The leadership-culture connection among Finnish managers. Leadership \& Organization Development Journal, 34(3), 250-270.

King, E. B., Botsford, W., Hebl, M. R., Kazama, S., Dawson, J. F., \& Perkins, A. (2012). Benevolent sexism at work: Gender differences in the distribution of challenging developmental experiences. Journal of Management, 38(6), 1835-1866.

McIntyre, C. (2016, September). The hidden costs of unlimited vacation policies. Benefits Canada. Retrieved from http://www.benefitscanada.com/human-resources/other/ the-hidden-costs-of- unlimited-vacation-policies-87402

Miner, K. N., Walker, J. M., Bergman, M. E., Jean, V. A., Carter-Sowell, A., January, S. C., \& Kaunas, C. (2018). From "her" problem to "our" problem: Using an individual lens versus a social-structural lens to understand gender inequity in STEM. Industrial and Organizational Psychology: Perspectives on Science and Practice, 11(2), 267-290.

Ohlott, P. J., Ruderman, M. N., \& McCauley, C. D. (1994). Gender differences in managers' developmental job experiences. Academy of Management Journal, 37(1), 46-67.

Oshry, B. (1999). Leading systems: Lessons from the power lab. Oakland, CA: Berrett-Koehler Publishers.

Piening, E. I., Baluchi, A. M., \& Ridder, H.-G. (2014). Mind the intended-implemented gap: Understanding employees' perceptions of HRM. Human Resource Management, 53(4), 545-567.

Smithson, J., \& Stokoe, E. H. (2005). Discourses of work-life balance: negotiating 'genderblind' terms in organizations. Gender, Work \& Organization, 12(2), 147-168.

Valerio, A. M., \& Sawyer, K. (2016, December). The men who mentor women. Harvard Business Review. Retrieved from https://hbr.org/2016/12/the-men-who-mentor-women 